\title{
Mobllity of Adsorbed Species in Zeolites: A Molecular Dynamics Simulation of Xenon in Silicalite
}

\author{
S. D. Pickett, ${ }^{*, \dagger}$ A. K. Nowak, ${ }^{\dagger}$ J. M. Thomas, ${ }^{\dagger}$ B. K. Peterson, ${ }^{\ddagger}$ J. F. P. Swift, ${ }^{\ddagger}$ A. K. Cheetham, ${ }^{\dagger,}$ \\ C. J. J. den Ouden, ${ }^{\S}$ B. Smit, ${ }^{\S}$ and M. F. M. Post ${ }^{\S}$
}

Davy Faraday Research Laboratory, The Royal Institution, 21 Albemarle Street, London WIX 4BS, United Kingdom, Chemical Crystallography Laboratory, University of Oxford, 9 Parks Road, Oxford OXI 3PD, United Kingdom, and Koninklijke/Shell-Laboratorium, Amsterdam (Shell Research B.V.), Badhuisweg 3, 1031 Amsterdam, The Netherlands (Received: August 30, 1989)

\begin{abstract}
Results from a molecular dynamics simulation of xenon in silicalite at $298 \mathrm{~K}$ and 4 atoms per unit cell $\left(\Delta U_{\mathrm{ads}}=-26.9 \mathrm{~kJ} / \mathrm{mol}\right.$, $\left.D=1.86 \times 10^{-9} \mathrm{~m}^{2} / \mathrm{s}\right)$ are in good agreement with the experimental value of $-24.5 \mathrm{~kJ} / \mathrm{mol}$ and the diffusion coefficient derived from the NMR pulsed field-gradient method $\left(4.00 \times 10^{-9} \mathrm{~m}^{2} / \mathrm{s}\right)$. The diffusivity is predicted to be negligible at temperatures around $77 \mathrm{~K}$ and then increases over the investigated range to $D=3.25 \times 10^{-9} \mathrm{~m}^{2} / \mathrm{s}$ at $450 \mathrm{~K}$, yielding an activation energy of $5.5 \mathrm{~kJ} / \mathrm{mol}$. Increasing the concentration from 4 to 16 atoms per unit cell results in a decreased internal energy of adsorption $(-28.1 \mathrm{~kJ} / \mathrm{mol})$ and a decreased diffusion coefficient $\left(D=0.37 \times 10^{-9} \mathrm{~m}^{2} / \mathrm{s}\right)$. The anisotropy of diffusion is also examined.
\end{abstract}

\section{Introduction}

Computer simulations of zeolite/adsorbate systems are currently of increasing importance in the context of understanding the catalytic properties of zeolites. They are used in conjunction with experimental techniques but possess the significant advantage that a wide range of conditions may be simulated, conditions which may be difficult to obtain in an experimental setup. Early work, ${ }^{1,2}$ based upon molecular mechanics procedures, employed simple atom-atom potentials to calculate heats of adsorption and adsorption isotherms and to estimate diffusion coefficients. More recently, adsorption sites and potential energy maps were calculated for xenon in zeolite rho, ${ }^{3}$ pyridine in zeolite $\mathrm{L},{ }^{4}$ and benzene in silicalite and zeolite theta-1.5 Monte Carlo simulations have been employed as a useful means of probing the potential energy space of zeolite/adsorbate systems as a function of temperature and sorbate concentration. Yashonath et al. examined the temperature dependence of the behavior of methane in zeolite $\mathrm{Y}^{6}$ and Smit and den Ouden the adsorption of methane in mordenite with variable zeolite composition. ${ }^{7}$ More recently the molecular dynamics (MD) technique has been applied to such systems with a view to obtaining time-dependent data such as diffusion coefficients for methane and benzene in zeolite $\mathrm{NaY}^{8,9}$ and water in ferrierite. $^{10}$ These studies have been based upon the approximation of a rigid zeolitic framework, but MD framework simulations of natrolite ${ }^{11}$ and zeolite $\mathrm{A}^{12}$ have been reported recently by Demontis et al.

The emergence of ${ }^{129} \mathrm{Xe}$ NMR as a means of probing the internal structure of zeolites ${ }^{13}$ and of exploring xenon as an adsorbate ${ }^{14}$ prompted us to investigate the silicalite/xenon system using the MD technique. There is also the added value that the diameter of xenon is close to that of methane, a molecule of increasing importance in heterogeneous catalysis. We developed three separate computer programs which were first used to investigate the test system, xenon in silicalite, at $298 \mathrm{~K}$ and a concentration of 4 xenon atoms per unit cell, followed by the use of the separate programs for varying the system temperature from 77 to $450 \mathrm{~K}$ and the adsorbate concentration from 4 to $16 \mathrm{ad}$ sorbate atoms per silicalite unit cell. We present calculated heats of adsorption, diffusion coefficients, an activation energy for diffusion, and xenon distributions in the channel system under these varied conditions, and make comparisons, where possible, with experimental data from uptake rate measurements and the pulsed field gradient NMR technique.

\footnotetext{
The Royal Institution

t University of Oxford

Koninklijke/Shell-Laboratorium
}

TABLE I: Lennard-Jones [6-12] Potential Parameters

\begin{tabular}{ccc}
\hline atom pair & $C, \mathrm{~kJ}^{6} \mathrm{~mol}^{-1}$ & $B, \mathrm{~kJ}^{12} \mathrm{~mol}^{-1}$ \\
\hline $\mathrm{Xe}-\mathrm{O}_{\text {zeol }}$ & $8.6143 \times 10^{3}$ & $1.1051 \times 10^{7}$ \\
$\mathrm{Xe}-\mathrm{Xe}$ & $3.3621 \times 10^{4}$ & $1.5139 \times 10^{8}$
\end{tabular}

Theory

Silicalite is the silica analogue of the synthetic zeolite catalyst ZSM-5. ${ }^{15}$ Its framework structure comprises two different channel systems, each defined by ten-membered rings. Straight channels with an elliptical cross section of approximately $5.7 \AA$ $\times 5.2 \AA$ are parallel to [010] and sinusoidal channels with a nearly circular cross section of $5.4 \AA$ run along [100]. The resulting intersections are elongated cavities up to $9 \AA$ in diameter. The crystallographic data for the silicalite structure were obtained by Lermer from a single-crystal X-ray diffraction study of ZSM-5 with $a=20.07 \AA, b=19.62 \AA$, and $c=13.65 \AA .^{16}$

Silicalite is assumed to exhibit no electric field on adsorbed species. Furthermore, due to the large size of oxygen compared to silicon in the $\mathrm{SiO}_{4}$ tetrahedra, it is assumed that silicon is effectively screened by oxygen and any short-range interaction between an adsorbate and silicon is negligible. All interaction energies are calculated by using simple Lennard-Jones [6-12]

(1) Kiselev, A. V. Adv. Chem. Ser. 1971, 102, 37

(2) Sargent, R. W. H.; Whitford, C. J. Adv. Chem. Ser. 1971, 102, 144

(3) Wright, P. A.; Thomas, J. M.; Ramdas, S.; Cheetham, A. K. J. Chem. Soc., Chem. Commun. 1984, 1338.

(4) Wright, P. A.; Thomas, J. M.; Cheetham, A. K.; Nowak, A. K. Nature 1985, 318, 611.

(5) Nowak, A. K.; Cheetham, A. K.; Pickett, S. D.; Ramdas, S. Mol. Simul. 1987, $1,67$.

(6) Yashonath, S.; Thomas, J. M.; Nowak, A. K.; Cheetham, A. K. Nature 1988, 331, 601.

(7) Smit, B.; den Ouden, C. J. J. J. Phys. Chem. 1988, 92, 7169

(8) Yashonath, S.; Demontis, P.; Klein, M. L. Chem. Phys. Lett. 1988, 153, 551 .

(9) Demontis, P.; Yashonath, S.; Klein, M. L. J. Phys. Chem. 1989, 93, 5016.

(10) Leherte, L.; Lie, G. C.; Swamy, K. N.; Clementi, E.; Derouane, E. G.; Andre, J. M. Chem. Phys. Lett. 1988, 145, 237.

(11) Demontis, P.; Suffriti, G. B.; Quartieri, S.; Fois, E. S.; Gamba, A Zeolites $1987,7,552$

(12) Demontis, P.; Suffriti, G. B.; Quartieri, S.; Fois, E. S.; Gamba, A. J. Phys. Chem. 1988, 92, 867 .

(13) Fraissard, J.; Ito, T.; Springuel-Huet, M.; Demarquay, J. In Proceedings of the 7th International Conference on Zeolites; Murakami, Y., lijima, A., Ward, J. W., Eds.; Kodansha/Elsevier: Tokyo, 1986; p 393. (14) Heink, W.; Kärger, J.; Pfeiffer, H.; Stallmach, F., submitted for publication in J. Am. Chem. Soc.

(15) Flanigen, E. M.; Bennett, J. M.; Grose, R. W.; Cohen, R. P.; Patton, R. L.; Kirchner, R. M.; Smith, J. V. Nature 1987, $271,512$.

(16) Lermer, H.; Draeger, M.; Steffen, J.; Unger, K. K. Zeolites 1985, 5 , 
TABLE II: Standard Conditions for the Xenon/Silicalite System

$\begin{array}{ll}\text { temp, K } & 298 \\ \text { simuln ensemble } & \text { NVT } \\ \text { xenon concn } & 4 / \text { unit cell of silicalite } \\ \text { simuln box } & 2 \times 2 \times 2 \text { unit cells } \\ & (40.14 \AA \times 39.84 \AA \times 27.30 \AA) \\ \text { time step, fs } & 10-12 \\ \text { cutoff radius for interacns, } \AA & 12.3\end{array}$

TABLE III: Calculated and Experimental Internal Energies of Adsorption and Diffusion Coefficients at $298 \mathrm{~K}$ and $4 \mathrm{Xe} /$ unit cell

\begin{tabular}{llcc}
\hline & & \multicolumn{2}{c}{ experiment } \\
\cline { 3 - 4 } & calculated & PFG-NMR & uptake rate \\
\hline$\Delta U_{\text {ads }}, \mathrm{kJ} / \mathrm{mol}$ & $-26.9 \pm 0.02$ & $\mathrm{na}$ & -24.5 \\
$D, 10^{-9} \mathrm{~m}^{2} / \mathrm{s}$ & $1.86 \pm 0.44$ & 4.00 & 0.10 \\
$\mathrm{ref}$ & this work & 14 & 20
\end{tabular}

potentials in the atom-atom approximation following the approach of Kiselev ${ }^{17}$ and assuming a rigid silicalite framework. The two sets of Lennard-Jones parameters are shown in Table I. In the MD technique, particle trajectories are followed by solving Newton's equations of motion for the particles using a finite difference approach. ${ }^{18}$ All our programs employ constant temperature variations of the Verlet algorithm with a time step in the order of $10 \mathrm{fs}\left(10^{-14} \mathrm{~s}\right) .^{19}$ Equilibration of the system was achieved in a 100-200-ps period after which data were collected for periods of 200 ps ( 96 and 128 xenon atoms) and 300-400 ps (32 xenon atoms).

The calculated properties of the xenon/silicalite system were chosen to facilitate the comparison with experimental observations. This is also the reason why the method of constant temperature, rather than constant energy, was chosen. In the experimental determination of diffusion coefficients the system is kept at a constant temperature, which means that the zeolite framework allows the transfer of energy between itself and the adsorbed phase. Internal energies and enthalpies of adsorption, $\Delta U_{\text {ads }}$ and $\Delta H_{\text {ads, }}$, are obtained from the averaged interaction energies calculated over several thousands of steps for every adsorbed atom. The mean square displacements, $\left\langle u_{x}{ }^{2}\right\rangle,\left\langle u_{y}{ }^{2}\right\rangle,\left\langle u_{z}{ }^{2}\right\rangle$, in the $x, y$, and $z$ directions and the overall mean square displacement, $\left\langle U^{2}\right\rangle$, are obtained from the total distance traveled, averaged over all particles. Anisotropic and overall diffusion coefficients may then be estimated by applying the Einstein relation. If we assume that diffusion in zeolites obeys the Arrhenius equation then an estimate of the activation energy for self-diffusion of xenon in silicalite is obtained from a plot of $\ln D$ versus $1 / T$. The trajectories of the adsorbed atoms in silicalite give information on preferred siting at certain temperatures. This is best illustrated as a plot of a probability distribution for xenon atoms in various directions within the zeolite crystal.

\section{Results and Discussion}

In order to confirm the correctness of the three computer programs, simulations were performed under the standard conditions listed in Table II. Thirty-two xenon atoms were placed in random positions inside the channels of the silicalite structure. The equilibration period was $100 \mathrm{ps}$ and data were collected over a further 300 ps. The mean values for the internal energy of adsorption and the overall diffusion coefficient calculated by using the three programs are given in Table III. The errors quoted represent the spread obtained by using different programs and three successive runs in one particular program. The agreement between calculated and experimental diffusion coefficients from NMR measurements is very good. The discrepancy of about an order of magnitude in the uptake rate measurement will be discussed below.

In the investigation of the temperature dependence of the system runs were performed with the same parameters as in the test case

(17) Kiselev, A. V.; Lopatkin, A. A.; Shulga, A. A. Zeolites 1985, 5, 261. (18) Allen, M. P.; Tildesley, D. J. Computer Simulation of Liquids; Clarendon Press: Oxford, U.K., 1987; Chapter 3.

(19) Verlet, L. Phys. Rev. 1976, 159, 98.
TABLE IV: Internal Energy of Adsorption and Diffusion Coefficient as a Function of Temperature at $4 \mathrm{Xe} /$ unit cell

\begin{tabular}{rccccc}
$T, \mathrm{~K}$ & $\begin{array}{c}\Delta U_{\mathrm{ads}}, \\
\mathrm{kJ} / \mathrm{mol}\end{array}$ & $\begin{array}{c}D, 10^{-9} \\
\mathrm{~m}^{2} / \mathrm{s}\end{array}$ & $T, \mathrm{~K}$ & $\begin{array}{c}\Delta U_{\text {ads, }} \\
\mathrm{kJ} / \mathrm{mol}\end{array}$ & $\begin{array}{c}D, 10^{-9} \\
\mathrm{~m}^{2} / \mathrm{s}\end{array}$ \\
\hline 77 & -28.8 & 0.03 & 298 & -26.9 & 1.86 \\
150 & -28.2 & 0.17 & 350 & -26.6 & 2.28 \\
200 & -27.8 & 0.60 & 450 & -25.9 & 3.25 \\
250 & -27.4 & 0.82 & & &
\end{tabular}

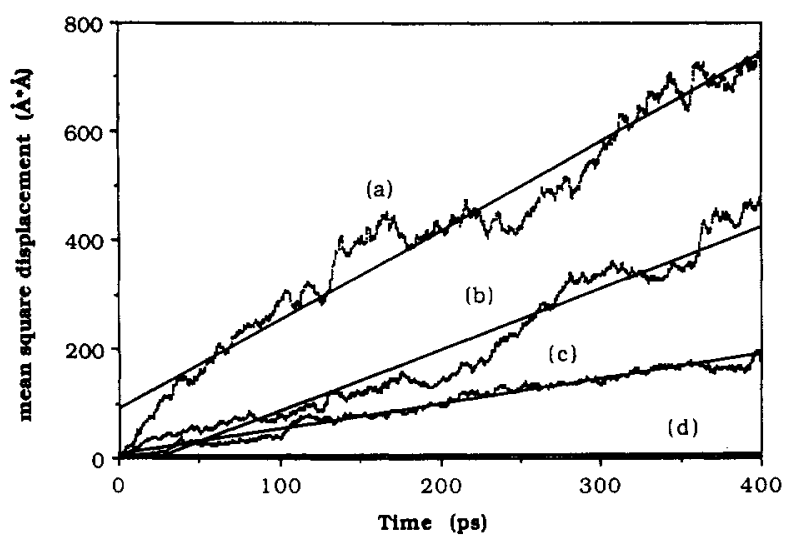

Figure 1. Xenon mean square displacement averaged over 32 atoms at $450 \mathrm{~K}(\mathrm{a}), 298 \mathrm{~K}(\mathrm{~b}), 200 \mathrm{~K}$ (c), and $77 \mathrm{~K}(\mathrm{~d})$.

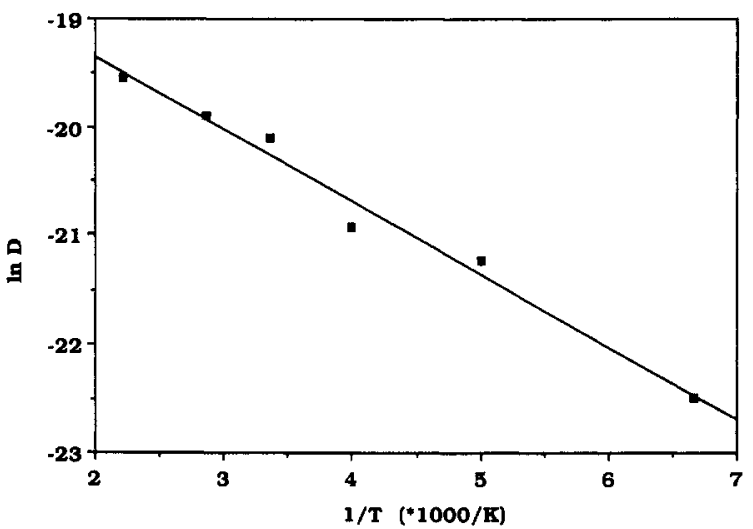

Figure 2. Dependence of the logarithm of the diffusion coefficient on inverse temperature.

but at different temperatures ranging from 77 to $450 \mathrm{~K}$. Table IV shows the calculated increase in internal energy of adsorption and an increase in diffusivity with increasing temperature. The reason for this effect is that at higher temperatures atoms have a higher kinetic energy, and greater velocities, and can therefore probe sites of higher (less favorable) potential energy. The variation in diffusion coefficients suggests that atoms are hardly moving at temperatures around $77 \mathrm{~K}$. This is confirmed by Figure 1 , showing the average xenon mean square displacement (MSD) as a function of time at $77,200,298$, and $450 \mathrm{~K}$. Although the MSD fluctuates about the fitted line for all temperatures, at 77 $\mathrm{K}$ the fluctuation is around a near-constant value, thus suggesting that xenon atoms remain in the vicinity of their starting position. A plot of $\ln D$ versus $1 / T$ is shown in Figure 2. A good fit to a straight line is obtained when the point at $77 \mathrm{~K}$ is neglected. We believe that this is a reasonable assumption as the time scale of our simulation is too short to obtain a good estimate of the diffusion at such a low temperature. The estimated energy of activation is $5.5 \mathrm{~kJ} / \mathrm{mol}$ and $D_{0}=1.5 \times 10^{-8} \mathrm{~m} / \mathrm{s}$. This compares well with an activation energy of $4.3 \pm 1.0 \mathrm{~kJ} / \mathrm{mol}$ obtained by Caro et al. for methane in $\mathrm{ZSM}-5,{ }^{21}$ but it is very low compared to the activation energy of about $20 \mathrm{~kJ} / \mathrm{mol}$ obtained for xenon in silicalite from recent uptake rate measurements. ${ }^{20}$

(20) Bülow, M.; Härtel, U.; Unger, K. K.; Müller, U, manuscript in preparation for submission to Zeolites. 


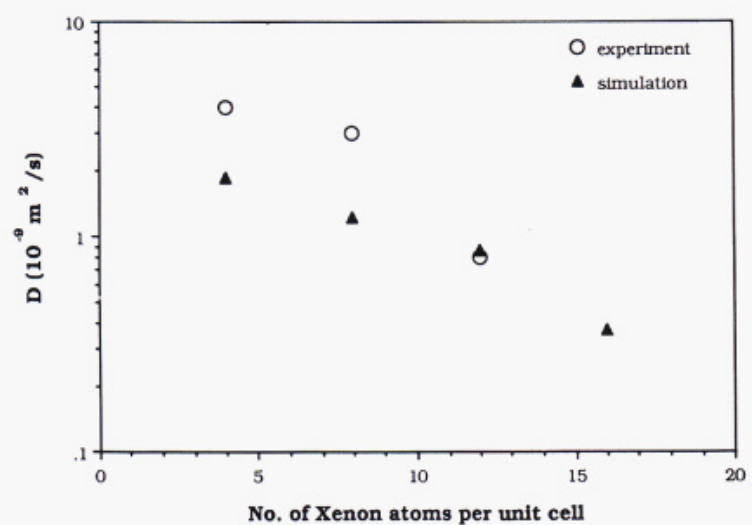

Figure 3. Experimental (O) (ref 14) and calculated ( $\mathbf{\Delta}$ ) diffusion coefficients at $298 \mathrm{~K}$ as function of the number of adsorbed Xe atoms per silicalite unit cell.
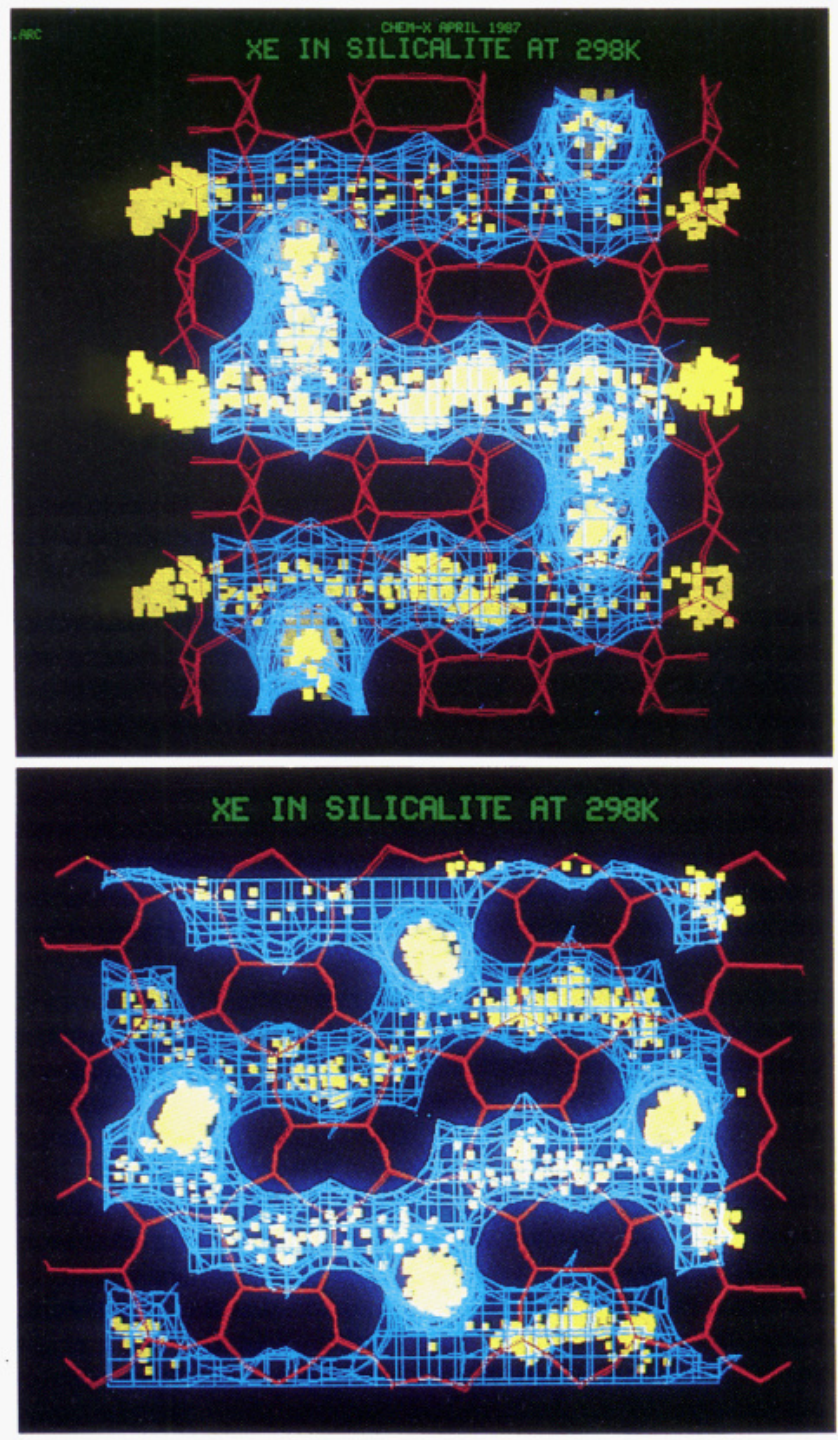

Figure 4. Trajectories of xenon at $298 \mathrm{~K}$ in the straight channels (top) and the sinusoidal channels of silicalite (bottom). Xenon center-of-mass positions are shown in yellow, $\mathrm{Si}-\mathrm{O}$ bonds are in red, and the internal zeolitic surface is represented by the blue net.

Runs were performed at $298 \mathrm{~K}$ with four xenon concentrations, $32,64,96$, and 128 xenon atoms in the simulation box $(4,8,12$, and 16 xenon atoms per unit cell). The decrease of internal energy of adsorption from $-26.9 \mathrm{~kJ} / \mathrm{mol}$ for 4 xenon atoms per unit cell to $-27.2,-27.6$, and $-28.1 \mathrm{~kJ} / \mathrm{mol}$ for 8,12 , and 16 atoms per

(21) Caro, J.; Bülow, M.; Schirmer, W.; Kärger, J.; Heink, W.; Pfeiffer, H.; Żdanov, S. P. J. Chem. Soc., Faraday Trans. 1 1986, 81, 2541.
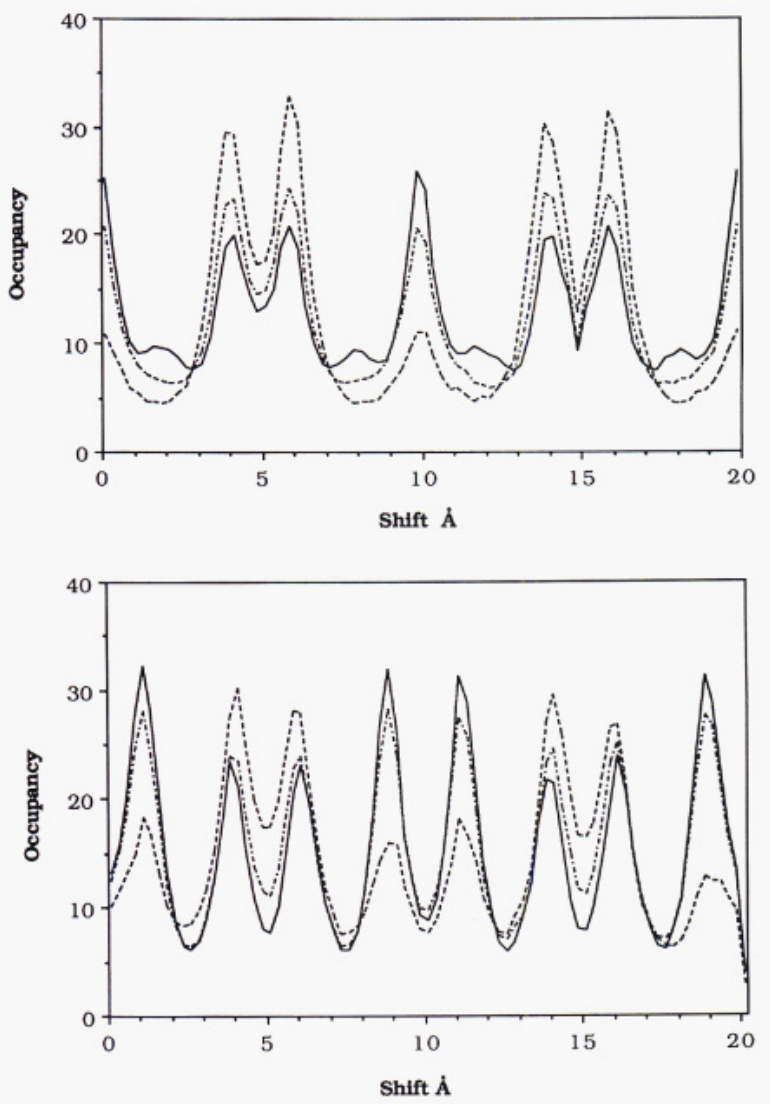

Figure 5. Distribution function of xenon at $298 \mathrm{~K}$ in the straight channel (a, upper) and the sinusoidal channel (b, lower) with $4(---), 12(-\cdot \cdot)$, and $16(-)$ xenon atoms per silicalite unit cell.

unit cell, respectively, is expected because of additional interatomic interactions. Accordingly, the diffusion coefficient decreases from $1.86 \times 10^{-9} \mathrm{~m}^{2} / \mathrm{s}$ to $1.23 \times 10^{-9} \mathrm{~m}^{2} / \mathrm{s}$ for 8 , to $0.87 \times 10^{-9} \mathrm{~m}^{2} / \mathrm{s}$ for 12 , and to $0.37 \times 10^{-9} \mathrm{~m}^{2} / \mathrm{s}$ for 16 xenon atoms per unit cell. The results suggest that a loading of 16 xenon atoms per unit cell of silicalite is possible but we assume that this value is close to the maximum packing. The diffusion coefficient at higher loading decreases as more xenon-xenon collisions occur, hindering diffusion. Comparison between our calculated data and those from PFG-NMR experiments ${ }^{14}$ in Figure 3 shows agreement to within a factor of 2 .

Separate diffusion coefficients for the $x, y$, and $z$ directions are of particular interest in zeolite systems because of the channels, which in the case of silicalite coincide with the $y$ (straight channels) and the $x$ direction (sinusoidal channels). The calculated diffusion coefficients at $298 \mathrm{~K}$ and 4 atoms per unit cell, $D_{x}=1.26 \times 10^{-9}$ $\mathrm{m}^{2} / \mathrm{s}, D_{y}=4.03 \times 10^{-9} \mathrm{~m}^{2} / \mathrm{s}$, and $D_{z}=0.28 \times 10^{-9} \mathrm{~m}^{2} / \mathrm{s}$, suggest that diffusion is fastest along the straight channel and slower along the sinusoidal channels. Diffusion along $z$ requires the alternating motion of atoms between straight and sinusoidal channels. The diffusion coefficient $D_{z}$ shows that this motion does occur but the small value suggests that we observe only occasional transitions of atoms from one channel system to the other. Values for the anisotropies of $D_{0}$ and the activation energy of diffusion are obtained from the temperature dependence of the separate diffusion coefficients: $D_{0}(x)=1.0 \times 10^{-8} \mathrm{~m}^{2} / \mathrm{s}, E_{\mathrm{act}}(x)=4.7 \mathrm{~kJ} / \mathrm{mol}$; $D_{0}(y)=3.4 \times 10^{-8} \mathrm{~m}^{2} / \mathrm{s}, E_{\text {act }}(y)=6.2 \mathrm{~kJ} / \mathrm{mol} ; D_{0}(z)=0.3 \times$ $10^{-8} \mathrm{~m}^{2} / \mathrm{s}, E_{\text {act }}(z)=5.5 \mathrm{~kJ} / \mathrm{mol}$. Thus, the rapid diffusion along $y$ and slow diffusion along $z$ comes from differences in the preexponential term rather than any large differences in diffusion barriers along the separate channels.

Trajectories of xenon along the straight and sinusoidal channels from the simulation of 32 xenon atoms at $298 \mathrm{~K}$ are shown in Figure 4. A large number of center-of-mass positions is observed around the midpoint between the intersections in both channel systems. To quantify this effect we have calculated the xenon distribution along the straight and sinusoidal channels by dividing 
the channels into segments of $\sim 0.25 \AA$ and counting the number of times a xenon atom occurs in that segment. The resulting distributions for the two channels are shown in Figure 5 for three different xenon concentrations at $298 \mathrm{~K}$, and the xenon count is shown starting from the center of an intersection with other intersections at approximately 10 and $20 \AA$. The complete range covers exactly one unit cell length in the appropriate direction. At low concentration we predict a high probability for xenon to be near the center of the two channels (double peaks at 5 and 15 $\AA$ ), but at higher concentrations packing constraints mean that xenon must also occupy the intersections. Further, the appearance at the highest loading of small peaks $2 \AA$ from the intersection peaks in the straight channel implies that additional atoms reside in the 10-rings. Occupancy of the center of the sinusoidal channel at the intersection is precluded by the proximity to atoms in the straight channel at the intersection. Atoms will therefore reside near the 10-rings at the junction of the sinusoidal channel and the intersection. This causes a double peak to occur at the intersection for the distribution along the sinusoidal channel.

Our results demonstrate that the MD technique is a useful computational tool in the investigation of the adsorption and diffusion of simple adsorbates in zeolites even when relatively small numbers of adsorbate atoms have to be used in the simulation. We obtain very good agreement between calculated and exper- imentally determined heats of adsorption and between computed diffusion coefficients and those determined by NMR techniques at $298 \mathrm{~K}$. The discrepancy between the NMR and our calculated values, and recent uptake rate measurements, may be explained by the fact that influences from either sorption heat release processes or surface barriers have not been finally excluded from these latter experiments. Nevertheless, the values are almost within 1 order of magnitude. Analysis of our results suggests that xenon occupies channel sites preferentially and that diffusion through the straight channel is the least hindered diffusion process. An increase in temperature generally results in faster diffusion; a higher concentration requires the occupation of the intersections by xenon and reduces the diffusivity. An estimated activation energy of $5.5 \mathrm{~kJ} / \mathrm{mol}$ predicts facile diffusion of xenon in silicalite but this value may be affected when a flexible framework approach is used.

Acknowledgment. We thank Dr. S. Yashonath for useful discussion. We thank the Science and Engineering Research Council (an equipment grant to J.M.T. and A.K.C. and a studentship to S.D.P.), Shell Research, Amsterdam (Postdoctoral Fellowship to A.K.N.), and the North Atlantic Treaty Organization (1987 Postdoctoral Fellowship to B.K.P.) for financial support. 